\title{
Vertebral derotation in adolescent idiopathic scoliosis causes hypokyphosis of the thoracic spine
}

\author{
Kota Watanabe ${ }^{1}$, Takayuki Nakamura ${ }^{3}$, Akio Iwanami ${ }^{2}$, Naobumi Hosogane ${ }^{2}$, Takashi Tsuji ${ }^{2}$, Ken Ishii ${ }^{2}$, \\ Masaya Nakamura², Yoshiaki Toyama², Kazuhiro $\mathrm{Chiba}^{2}$ and Morio Matsumoto ${ }^{2 *}$
}

\begin{abstract}
Background: The purpose of this study was to test the hypothesis that direct vertebral derotation by pedicle screws (PS) causes hypokyphosis of the thoracic spine in adolescent idiopathic scoliosis (AIS) patients, using computer simulation.

Methods: Twenty AIS patients with Lenke type 1 or 2 who underwent posterior correction surgeries using PS were included in this study. Simulated corrections of each patient's scoliosis, as determined by the preoperative CT scan data, were performed on segmented 3D models of the whole spine. Two types of simulated extreme correction were performed: 1) complete coronal correction only (C method) and 2) complete coronal correction with complete derotation of vertebral bodies (C+D method). The kyphosis angle (T5-T12) and vertebral rotation angle at the apex were measured before and after the simulated corrections.

Results: The mean kyphosis angle after the $C+D$ method was significantly smaller than that after the $C$ method $\left(2.7 \pm 10.0^{\circ}\right.$ vs. $\left.15.0 \pm 7.1^{\circ}, p<0.01\right)$. The mean preoperative apical rotation angle of $15.2 \pm 5.5^{\circ}$ was completely corrected after the $C+D$ method $\left(0^{\circ}\right)$ and was unchanged after the $C$ method $\left(17.6 \pm 4.2^{\circ}\right)$.

Conclusions: In the 3D simulation study, kyphosis was reduced after complete correction of the coronal and rotational deformity, but it was maintained after the coronal-only correction. These results proved the hypothesis that the vertebral derotation obtained by PS causes hypokyphosis of the thoracic spine.
\end{abstract}

\section{Background}

Posterior correction and fusion surgery with a segmental pedicle screw (PS) construct has been widely utilized for the surgical treatment of patients with adolescent idiopathic scoliosis (AIS), because it allows for better curve correction in the coronal plane [1-4] and the axial planes with direct vertebral rotation (DVR), compared with the use of hook or hybrid constructs [5,6]. However, a postoperative decrease in thoracic kyphosis has been reported in association with posterior correction surgery using a PS construct $[7,8]$. While slight increases in thoracic kyphosis have been obtained using a hook construct [9-14], PS constructs are reported to decrease the thoracic kyphosis by $3^{\circ}-14^{\circ}$ after surgery $[2,3,13,15,16]$. However, previous

\footnotetext{
* Correspondence: morio@sc.itc.keio.ac.jp

${ }^{2}$ Department of Orthopaedic Surgery, Keio University, Tokyo, Japan

Full list of author information is available at the end of the article
}

studies have also shown that PS constructs produce a significantly better vertebral derotation effect than hook-androd constructs [5,6,17]. The mean derotation angle obtained with a PS construct is reported to be 7.1-13.0 $[5,18,19]$, while it is $0.4^{\circ}-3.6^{\circ}$ [20-26] with a hook-and-rod construct and $1.9^{\circ}-4.2^{\circ}$ with the sublaminar wiring technique $[27,28]$. We therefore hypothesized that the decrease in thoracic kyphosis after posterior correction surgery using PS constructs was associated with the correction of vertebral rotation. The purpose of this study was to test this hypothesis by analyzing computersimulated corrections, using three-dimensional (3D) scoliosis models based on CT data from patients with AIS.

\section{Methods}

Twenty consecutive AIS patients (all female) who underwent posterior correction and fusion surgeries with a segmental PS construct between November 2008 and

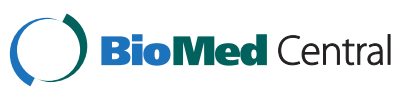


October 2009 were included in this study. All the patients had a major thoracic curve (Lenke type 1: 15 patients; type 2: 5 patients). The mean age at the time of surgery was $15.9 \pm 3.2$ years (range, $12-23$ years). The mean preoperative Cobb angle of the main thoracic curve was $58 \pm 13^{\circ}$ (range, $41-81^{\circ}$ ), and the mean preoperative thoracic kyphosis (T5-12) was $18.9 \pm 7.5^{\circ}$ (range, 4.1-28.8 ${ }^{\circ}$ on standing radiographs. The $3 \mathrm{D}$ computer simulation was conducted for all the patients.

The simulated corrections of scoliosis for each patient were performed on segmented 3D models of the whole scoliotic spine, created using 3D image processing software (Mimics; Materialise NV, Belgium) and based on a 1-mmthick preoperative CT scan slice. Each segmented 3D model of the whole spine was created as follows: First, a 3D surface-reconstruction model of the whole spine was created from the CT data (Image 1). Then, the L5 vertebra was extracted from Image 1 using the range of interest (ROI) edit function of the software, to create a segmented L5 vertebra. The same procedure was repeated for each vertebra from L5 to T1 to create a segmented 3D model of the whole spine (Figure 1). In the segmented 3D spine model, each vertebra could be manipulated independently. The simulated correction was then performed in two different ways: 1 ) complete coronal correction (C correction), and 2) complete coronal correction with complete axial derotation of vertebra ( $\mathrm{C}+\mathrm{D}$ correction), as described below.

Complete coronal correction ( $C$ correction) (Figure 2$)$ : First, the mid-sagittal plane of the whole spine was defined as the plane that included three anatomical landmark
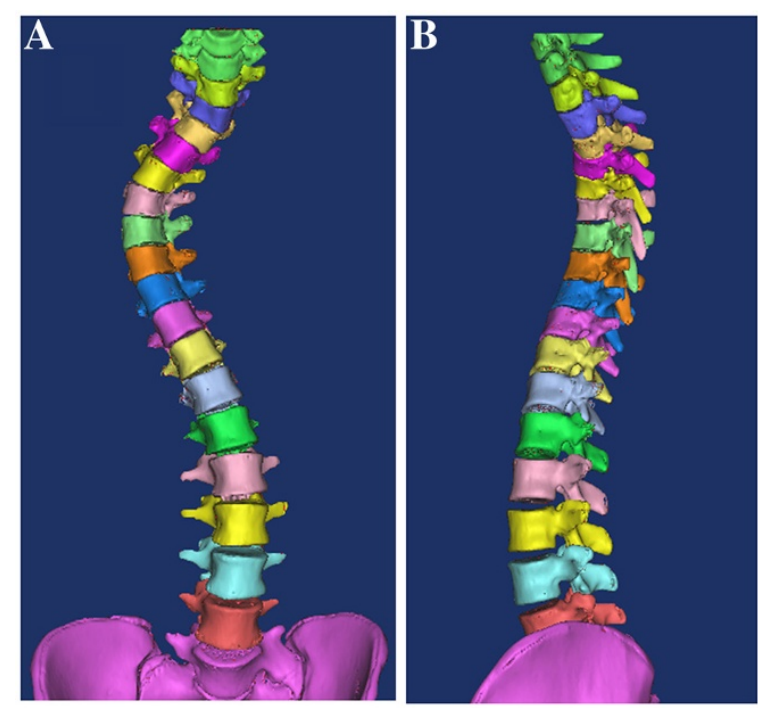

Figure 1 Segmented 3D spine model. A: Frontal view. B: Lateral view. A segmented 3D model of the whole spine, in which is each vertebra could be manipulated independently, was created using 3D image-processing software (Mimics; Materialise NV, Belgium), and based on the preoperative CT scan data.

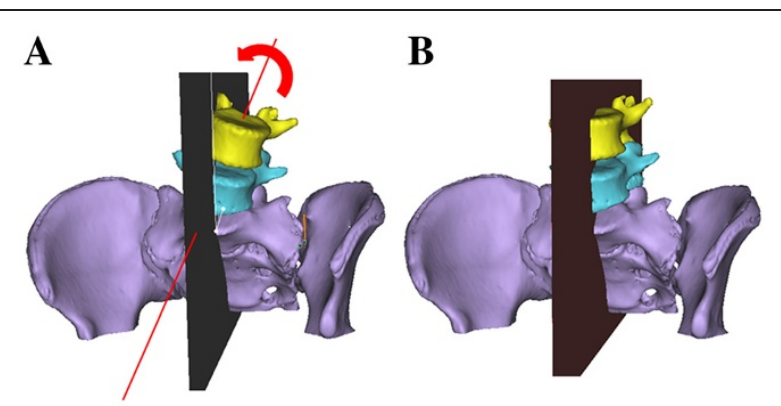

Figure 2 Simulated coronal correction using the 3D segmented spine model. A: Before correction of the L5 vertebra. B: After correction of the $L 5$ vertebra. The coronal correction was performed by rotating the vertebra around an axis consisting of intersecting points between the mid-sagittal plane and the anterior and posterior margin of the upper endplate of the lower vertebra (S1), thus constraining the correction to the coronal plane $(\mathbf{A})$. The correction was continued until the upper endplate of the L5 vertebra became horizontal (B).

points: one at the center of the posterior vertebral wall of C7, and two at the centers of the anterior and posterior margins of the upper sacral endplate. The correction was started from the L5 vertebra and performed by rotating the L5 vertebra around the axis consisting of the intersecting points between the mid-sagittal plane and the anterior and posterior margin of the upper endplate of the lower vertebra (S1), thus constraining the correction to the coronal plane (Figure 2A). The correction was continued until the upper endplate of the L5 vertebra became horizontal (Figure 2B). During the correction, the vertebrae cranial to L5 were rotated together with the L5 vertebra, maintaining their original relative position. The same correction procedures were continued to $\mathrm{C} 7$, to align the whole spine on the mid-sagittal plane.

Complete coronal correction with complete axial derotation of the vertebrae $(C+D$ correction) (Figure 3$)$ : First, a "reference plane" defined as the plane including three points, one at the central notch of the lamina and two at the center of the upper and lower endplates on the posterior vertebral wall (Figure 3A), was determined for each vertebra from T1 to L5. Then, an "intervertebral axis," defined as a line intersecting the neighboring reference planes was determined (Figure $3 \mathrm{~B}$ ). The simulated correction was performed by rotating each vertebra around the intervertebral axis until the neighboring vertebral reference planes became matched on the same plane (Figure $3 \mathrm{C}$ and D). The simulated correction was started at L5 and continued to T1. During the correction, the vertebrae cranial to the vertebra being corrected were rotated together with it, thus maintaining their original relative position. These corrections resulted in the complete coronal correction and axial derotation of the vertebrae (Figure 3D).

To evaluate the relationship between thoracic kyphosis and vertebral derotation, the thoracic kyphosis angle 


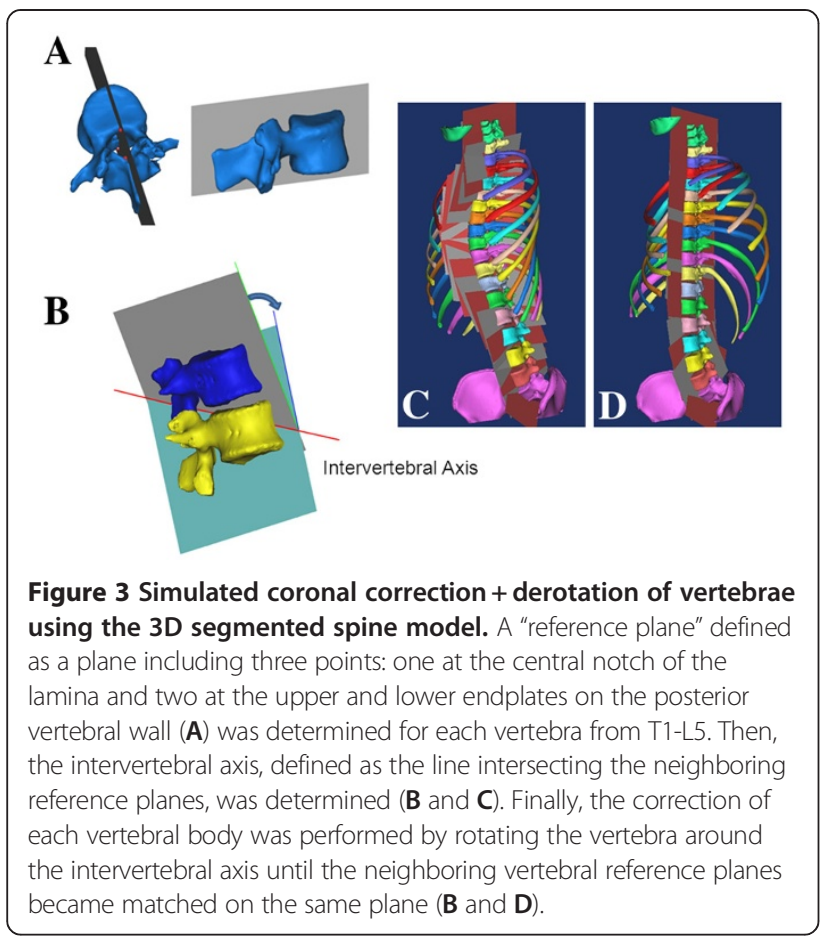

(T5-12), the radius of the thoracic curvature, and the vertebral rotation angle at the apex were measured before and after the two different simulated corrections for each patient. The thoracic kyphosis angle and radius of thoracic curvature were measured on the mid-sagittal plane. The radius of curvature at a given point is the radius of a circle that mathematically best fits the spinal curve at that point. The radius of curvature was measured at each adjacent segment from T1-T12, and then a value for the whole thoracic spine was determined as the mean of the values for each segment. The vertebral rotation angle at the apex was measured using Aaro's method [29] against a reference point set at the pelvis. The clinical relevance of these simulated corrections was evaluated by comparing the values obtained from the simulations with those measured on the postoperative CT taken for each patient.

Surgical procedures included the segmental placement of the PS, placement of the first rod on the concave side of the curve, rod rotation maneuver for the sagittal and coronal corrections, in-situ contouring for coronal correction, direct vertebral derotation for axial correction, and placement of the second rod, as described previously [18,30,31].

This study was approved by the medical ethics committee of Keio University Hospital (2009-203-2).

\section{Results}

The mean kyphosis angle before the simulated correction was $11.2 \pm 6.4$, and it increased significantly to $15.0 \pm 7.1$, after the $C$ correction $(p=0.02)$. However, the mean

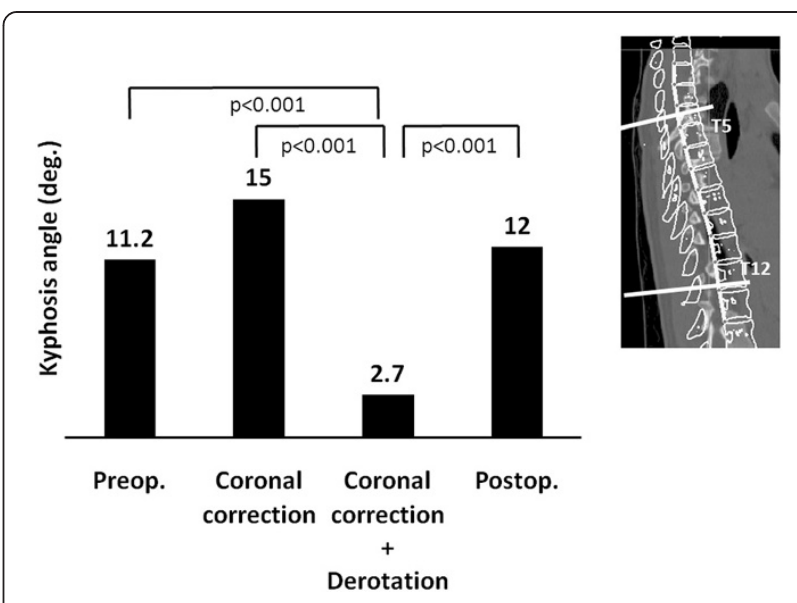

Figure 4 Kyphosis angle after simulated corrections and postoperative findings.

thoracic kyphosis angle decreased significantly to $2.7 \pm 10.0$ after the $\mathrm{C}+\mathrm{D}$ correction $(\mathrm{p}<0.001)$ (Figure 4). The mean radius of curvature of the thoracic spine before the simulated correction was $1660 \pm 1461 \mathrm{~mm}$ (Figure 5). Although the value increased significantly, to $12248 \pm 30543 \mathrm{~mm}$ after the $\mathrm{C}+\mathrm{D}$ correction, no significant change was recognized after the $C$ correction $(832 \pm 552 \mathrm{~mm}, \mathrm{p}=0.617)$. The mean radius of curvature was significantly different between the two correction methods $(\mathrm{p}<0.001)$. The mean vertebral rotation angle at the apex was $15.2 \pm 5.5$ before the simulated correction (Figure 6), and it was 0 (completely corrected) after the $\mathrm{C}+\mathrm{D}$ simulation. After the $C$ correction, however, the mean rotation angle of the apex did not change significantly $(17.6 \pm 4.2, p=0.209)$. The CT scans obtained after the patients' posterior correction and fusion surgery with a segmental PS construct revealed a mean kyphosis angle of $12.0 \pm 7.4$ (Figure 4), a mean radius

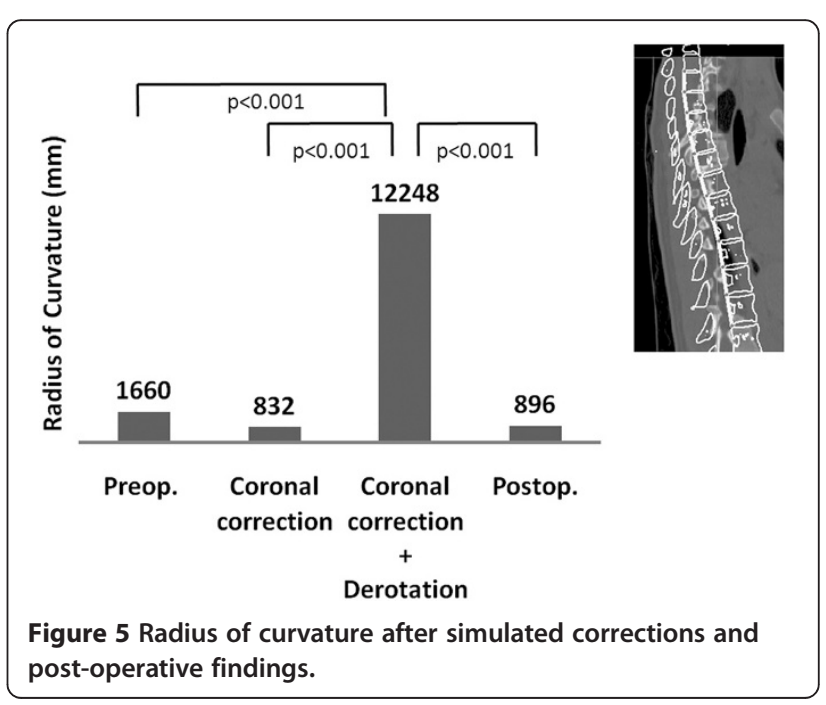




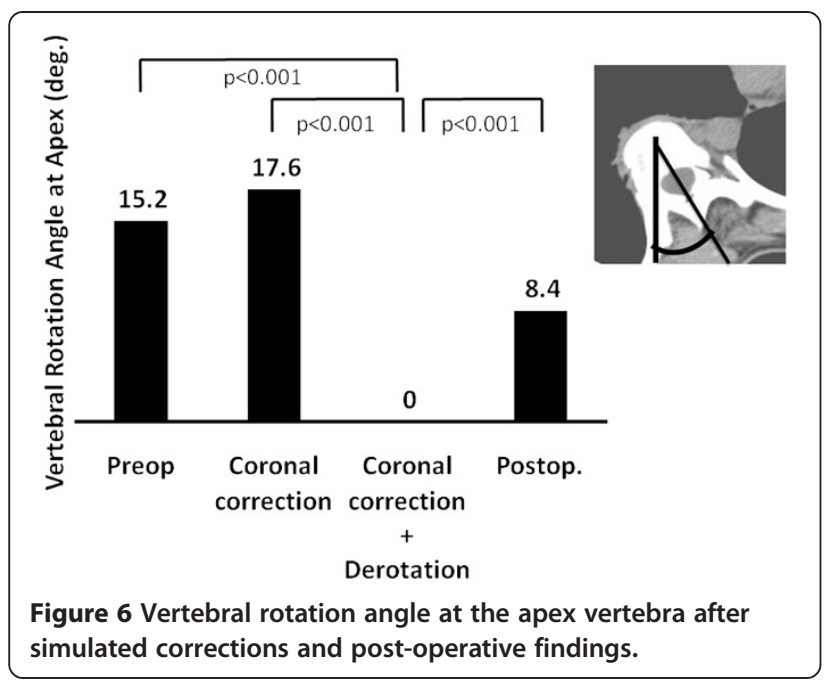

of curvature of $896 \pm 373 \mathrm{~mm}$ (Figure 5), and a mean apical rotation angle of $8.4 \pm 4.5$ (Figure 6).

\section{Discussion}

The results of the 3D simulation study indicated a close relationship between vertebral derotation and a decrease in thoracic kyphosis, since the $\mathrm{C}+\mathrm{D}$ simulation resulted in a significant decrease in thoracic kyphosis, while the $\mathrm{C}$ correction resulted in the maintenance of thoracic kyphosis. The decrease in thoracic kyphosis caused by vertebral derotation may be attributed partly to the wedge deformity of the vertebral bodies, which are taller on the convex side than on the concave side and taller ventrally than posteriorly in patients with structural scoliosis (Figure 7)
$[32,33]$. During the correction surgery, the vertebral derotation maneuver causes both the taller convex wall and the taller anterior wall to shift in the ventral direction, thereby elongating the anterior column of the thoracic spine and ultimately resulting in a decrease in thoracic kyphosis (Figure 7).

Segmented 3D scoliosis models have been used in previous studies to reproduce actual scoliotic spine deformities and correction maneuvers, including Cotrel-Dubousset surgical maneuvers, in situ contouring, and correction with a segmental PS construct using a personalized finite element model of AIS [3437]. The objective of these simulations was to predict the corrected spinal geometry and to assist the preoperative planning of the surgical instrumentation to be used. However, the segmented 3D scoliosis model created in the present study eliminates the constraining effects of soft tissues, to simulate the maximum corrections in the coronal plane independent of corrections in the axial plane, which cannot be accomplished in the actual surgery. Therefore, we also evaluated the clinical relevance of this simulation model. The mean rotation angle at the apex measured on patients' post-surgical CT images was between the mean values obtained by the simulated $\mathrm{C}$ correction and the simulated $\mathrm{C}+\mathrm{D}$ correction (Figure 6). The mean thoracic kyphosis angle and radius of curvature were also between the mean values of the two simulated corrections (Figures 4 and 5). These results suggest that the real surgery can achieve a limited correction in the axial plane that falls between the two extremes of the simulated corrections.

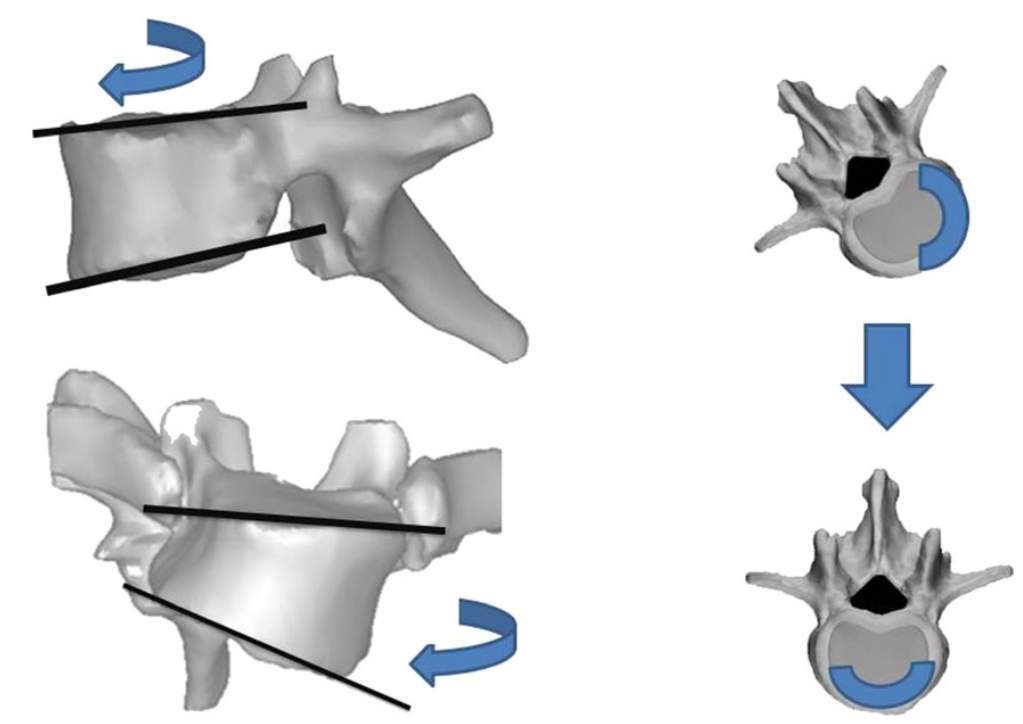

Figure 7 Wedge deformity of a vertebral body in the scoliotic spine. T9 vertebra of a 12-year-old girl with AIS. The wedged vertebra is taller at the anterior than the posterior wall, and at the convex side than the concave side. During vertebral derotation, the taller anterior and convex walls shift in the ventral direction of the spine. 


\section{Conclusions}

In conclusion, the present 3D simulation study demonstrated that the derotation of vertebrae caused a decrease in thoracic kyphosis during the correction of thoracic scoliosis.

\section{Consent}

Written informed consent was obtained from the parents of the patient for publication of this case report and any accompanying images. A copy of the written consent is available for review from the Editor-in-Chief of this journal.

\section{Competing interests}

The authors declare that they have no competing interests.

\section{Author details}

'Department of Advanced Therapy for Spine and Spinal Cord Disorders, Keio University, Tokyo, Japan. ${ }^{2}$ Department of Orthopaedic Surgery, Keio University, Tokyo, Japan. ${ }^{3}$ DePuy Japan, Johnson \& Johnson KK, Tokyo, Japan.

\section{Authors' contributions}

KW, MM and TN made substantial contributions to the conception and design, and the acquisition, analysis, and interpretation of data. They were also involved in drafting and revising the manuscript. Al, $\mathrm{NH}, \mathrm{TT}, \mathrm{KI}, \mathrm{MN}, \mathrm{YT}$, and KC contributed to the conception and design, and performed critical revision of the manuscript. All authors read and approved the final manuscript.

Received: 25 December 2011 Accepted: 12 June 2012

Published: 12 June 2012

\section{References}

1. Suk SI, Kim WJ, Kim JH, Lee SM: Restoration of thoracic kyphosis in the hypokyphotic spine: a comparison between multiple-hook and segmental pedicle screw fixation in adolescent idiopathic scoliosis. J Spinal Disord 1999, 12:489-495.

2. Kim YJ, Lenke LG, Cho SK, Bridwell KH, Sides B, Blanke K: Comparative analysis of pedicle screw versus hook instrumentation in posterior spinal fusion of adolescent idiopathic scoliosis. Spine (Phila Pa 1976) 2004, 29:2040-2048.

3. Kim YJ, Lenke LG, Kim J, Bridwell KH, Cho SK, Cheh G, Sides B: Comparative analysis of pedicle screw versus hybrid instrumentation in posterior spinal fusion of adolescent idiopathic scoliosis. Spine (Phila Pa 1976) 2006, 31:291-298

4. Lowenstein JE, Matsumoto H, Vitale MG, Weidenbaum M, Gomez JA, Lee FY, Hyman JE, Roye DP Jr: Coronal and sagittal plane correction in adolescent idiopathic scoliosis: a comparison between all pedicle screw versus hybrid thoracic hook lumbar screw constructs. Spine (Phila Pa 1976) 2007, 32:448-452.

5. Asghar J, Samdani AF, Pahys JM, D'Andrea LP, Guille JT, Clements DH, Betz RR: Computed tomography evaluation of rotation correction in adolescent idiopathic scoliosis: a comparison of an all pedicle screw construct versus a hook-rod system. Spine (Phila Pa 1976) 2009, 34:804-807.

6. Fu G, Kawakami N, Goto M, Tsuji T, Ohara T, Imagama S: Comparison of vertebral rotation corrected by different techniques and anchors in surgical treatment of adolescent thoracic idiopathic scoliosis. J Spinal Disord Tech 2009, 22:182-189.

7. Vora V, Crawford A, Babekhir N, Boachie-Adjei O, Lenke L, Peskin M, Charles G, Kim Y: A pedicle screw construct gives an enhanced posterior correction of adolescent idiopathic scoliosis when compared with other constructs: myth or reality. Spine (Phila Pa 1976) 2007, 32:1869-1874.

8. Clement JL, Chau E, Kimkpe C, Vallade MJ: Restoration of thoracic kyphosis by posterior instrumentation in adolescent idiopathic scoliosis: comparative radiographic analysis of two methods of reduction. Spine (Phila Pa 1976) 2008, 33:1579-158.

9. Bridwell KH, Betz R, Capelli AM, Huss G, Harvey C: Sagittal plane analysis in idiopathic scoliosis patients treated with Cotrel-Dubousset instrumentation. Spine (Phila Pa 1976) 1990, 15:921-926.

10. Lenke LG, Bridwell KH, Baldus C, Blanke K, Schoenecker PL: CotrelDubousset instrumentation for adolescent idiopathic scoliosis. J Bone Joint Surg Am 1992, 74:1056-1067.

11. Betz RR, Harms J, Clements DH, Lenke LG 3rd, Lowe TG, Shufflebarger HL, Jeszenszky D, Beele B: Comparison of anterior and posterior instrumentation for correction of adolescent thoracic idiopathic scoliosis. Spine (Phila Pa 1976) 1999, 24:225-239.

12. Leung JP, Lam TP, Ng BK, Cheng JC: Posterior ISOLA segmental spinal system in the treatment of scoliosis. J Pediatr Orthop 2002, 22:296-301.

13. Rhee JM, Bridwell KH, Won DS, Lenke LG, Chotigavanichaya C, Hanson DS: Sagittal plane analysis of adolescent idiopathic scoliosis: the effect of anterior versus posterior instrumentation. Spine (Phila Pa 1976) 2002, 27:2350-2356.

14. Willers U, Transfeldt EE, Hedlund R: The segmental effect of Cotrel-Dubousset instrumentation on vertebral rotation, rib hump and the thoracic cage in idiopathic scoliosis. Eur Spine J 1996, 5:387-393.

15. Kuklo TR, Potter BK, Lenke LG: Vertebral rotation and thoracic torsion in adolescent idiopathic scoliosis: what is the best radiographic correlate? J Spinal Disord Tech 2005, 18:139-147.

16. Potter BK, Kuklo TR, Lenke LG: Radiographic outcomes of anterior spinal fusion versus posterior spinal fusion with thoracic pedicle screws for treatment of Lenke Type I adolescent idiopathic scoliosis curves. Spine (Phila Pa 1976) 2005, 30:1859-1866.

17. Cheng I, Hay D, lezza A, Lindsey D, Lenke LG: Biomechanical analysis of derotation of the thoracic spine using pedicle screws. Spine (Phila Pa 1976) 2010, 35:1039-1043.

18. Lee SM, Suk SI, Chung ER: Direct vertebral rotation: a new technique of three-dimensional deformity correction with segmental pedicle screw fixation in adolescent idiopathic scoliosis. Spine (Phila Pa 1976) 2004 29:343-349.

19. Vallespir GP, Flores JB, Trigueros IS, Sierra EH, Fernandez PD, Olaverri JC, Alonso MG, Galea RR, Francisco AP, de Rodriguez Paz B, et al: Vertebral coplanar alignment: a standardized technique for three dimensional correction in scoliosis surgery: technical description and preliminary results in Lenke type 1 curves. Spine (Phila Pa 1976) 2008, 33:1588-1597.

20. Dumas R, Steib JP, Mitton D, Lavaste F, Skalli W: Three-dimensional quantitative segmental analysis of scoliosis corrected by the in situ contouring technique. Spine (Phila Pa 1976) 2003, 28:1158-1162.

21. Wojcik AS, Webb JK, Burwell RG: Harrington-Luque and Cotrel-Dubousset instrumentation for idiopathic thoracic scoliosis. A postoperative comparison using segmental radiologic analysis. Spine (Phila Pa 1976) 1990, 15:424-431.

22. Cundy PJ, Paterson DC, Hillier TM, Sutherland AD, Stephen JP, Foster BK: Cotrel-Dubousset instrumentation and vertebral rotation in adolescent idiopathic scoliosis. J Bone Joint Surg Br 1990, 72:670-674.

23. Ecker ML, Betz RR, Trent PS, Mahboubi S, Mesgarzadeh M, Bonakdapour A Drummond DS, Clancy M: Computer tomography evaluation of CotrelDubousset instrumentation in idiopathic scoliosis. Spine (Phila Pa 1976) 1988, 13:1141-1144.

24. Gray JM, Smith BW, Ashley RK, LaGrone MO, Mall J: Derotational analysis of Cotrel-Dubousset instrumentation in idiopathic scoliosis. Spine (Phila Pa 1976) 1991, 16:S391-S393.

25. Lenke $L G$, Bridwell $K H$, Baldus $C$, Blanke $K$ : Analysis of pulmonary function and axis rotation in adolescent and young adult idiopathic scoliosis patients treated with Cotrel-Dubousset instrumentation. J Spinal Disord 1992, 5:16-25

26. Wood KB, Transfeldt EE, Ogilvie JW, Schendel MJ, Bradford DS: Rotational changes of the vertebral-pelvic axis following Cotrel-Dubousset instrumentation. Spine (Phila Pa 1976) 1991, 16:S404-S408.

27. Marchesi DG, Transfeldt EE, Bradford DS, Heithoff KB: Changes in vertebral rotation after Harrington and Luque instrumentation for idiopathic scoliosis. Spine (Phila Pa 1976) 1992, 17:775-780.

28. Wood KB, Olsewski JM, Schendel MJ, Boachie-Adjei O, Gupta M: Rotational changes of the vertebral pelvic axis after sublaminar instrumentation in adolescent idiopathic scoliosis. Spine (Phila Pa 1976) 1997, 22:51-57.

29. Aaro S, Dahlborn M: Estimation of vertebral rotation and the spinal and rib cage deformity in scoliosis by computer tomography. Spine (Phila Pa 1976) 1981, 6:460-467.

30. Kim YJ, Lenke LG, Bridwell KH, Cho YS, Riew KD: Free hand pedicle screw placement in the thoracic spine: is it safe? Spine (Phila Pa 1976) 2004, 29:333-342. discussion 342 
31. Watanabe K, Matsumoto M, Tsuji T, Ishii K, Takaishi H, Nakamura M, Toyama Y, Chiba K: Ball tip technique for thoracic pedicle screw placement in patients with adolescent idiopathic scoliosis. J Neurosurg Spine 2010, 13:246-252.

32. Guo X, Chau WW, Chan YL, Cheng JC: Relative anterior spinal overgrowth in adolescent idiopathic scoliosis. Results of disproportionate endochondral-membranous bone growth. J Bone Joint Surg Br 2003, 85:1026-1031.

33. Parent S, Labelle H, Skalli W, Latimer B, de Guise J: Morphometric analysis of anatomic scoliotic specimens. Spine (Phila Pa 1976) 2002, 27:2305-2311.

34. Aubin CE, Petit Y, Stokes IA, Poulin F, Gardner-Morse M, Labelle H: Biomechanical modeling of posterior instrumentation of the scoliotic spine. Comput Methods Biomech Biomed Engin 2003, 6:27-32.

35. Lafage V, Dubousset J, Lavaste F, Skalli W: 3D finite element simulation of Cotrel-Dubousset correction. Comput Aided Surg 2004, 9:17-25.

36. Dumas R, Lafage V, Lafon Y, Steib JP, Mitton D, Skalli W: Finite element simulation of spinal deformities correction by in situ contouring technique. Comput Methods Biomech Biomed Engin 2005, 8:331-337.

37. Aubin CE, Labelle H, Chevrefils C, Desroches G, Clin J, Eng AB: Preoperative planning simulator for spinal deformity surgeries. Spine (Phila Pa 1976) 2008, 33:2143-2152.

doi:10.1186/1471-2474-13-99

Cite this article as: Watanabe et al: Vertebral derotation in adolescent idiopathic scoliosis causes hypokyphosis of the thoracic spine. BMC Musculoskeletal Disorders 2012 13:99.

\section{Submit your next manuscript to BioMed Central and take full advantage of:}

- Convenient online submission

- Thorough peer review

- No space constraints or color figure charges

- Immediate publication on acceptance

- Inclusion in PubMed, CAS, Scopus and Google Scholar

- Research which is freely available for redistribution 